GHANA JOURNAL OF DEPARTMENT OF HEALTH, PHYSICAL EDUCATION AND RECREATION, SPORTS AND DANCE (GJOHPERSD)

Volume 10, Year 2017

A JOURNAL OF THE DEPARTMENT OF HEALTH, PHYSICAL EDUCATION AND RECREATION (HPER)

UNIVERSITY OF CAPE COAST

GHANA, WEST AFRICA 


\title{
Efficacy of Combined Therapy of Cognitive Restructuring and Study Skills Counselling on Test Anxiety among Senior High School Students in Ghana
}

\author{
Barbara Frimpong Manso, Godwin Awabil* \\ \& Edward Kofi Ntim \\ 1 Department of Guidance and Counselling \\ 2 Counselling Centre \\ ${ }^{3}$ Department of Education and Psychology \\ University of Cape Coast, Ghana
}

Corresponding author's email: gawabil1@ucc.edu.gh and phone number: +233246573716

\begin{abstract}
Test anxiety is a serious problem for many students. It is a major obstacle to academic performance. In view of this, it is necessary to help students manage test anxiety through psychological interventions. This study investigated the combined effects of cognitive restructuring therapy and study skills counselling on test anxiety among senior high school students in Ghana. The population for this study was all second year senior high School students in the Komenda Edina Eguafo Abrem Municipality. Quasi-experimental, pre-test, post-test control group design guided the study. Simple random sampling technique was used to select 40 respondents to participate in the study. Two research hypotheses were formulated for the study and tested at 0.05 level of significance. The data were analysed using independent samples $t$ test. The study revealed that cognitive restructuring and study skills counselling had significant effect on the test anxiety of participants in the experimental group at post-test when compared with the control. Again, the results showed that there was no significant influence of gender on the test anxiety scores of the
\end{abstract}


Efficacy of Combined Therapy of Cognitive Restructuring and Study Skills Counselling on Test Anxiety among Senior High School Students in Ghana

participants in the experimental group at post-test. Based on the findings, it was recommended that counsellors should make use of cognitive restructuring and study skills counselling in order to reduce or manage test anxiety among senior high school students.

Keywords: Test anxiety; cognitive restructuring; study skills counselling; quasi-experimental; senior high school students 


\section{Introduction}

From the time we are born till the time we depart from the world, anxiety is experienced. This is because life is full of challenges and without effective coping skills, the result is anxiety. According to Ngwoke, Ossai and Obikwelu (2013), anxiety is one of the emotional components of human life. Every task performance to an extent is accomplished by some measures of anxiety. Anxiety is regarded as a common psychological problem among human beings with physical, emotional and social manifestations. One of the types of anxiety that affects students is called test anxiety.

Test anxiety has been defined in several ways. Test anxiety is the physiological state of the mind of a candidate about a test as expressed by the level of worry, fear, uncertainty, concern and hopelessness before and during a test or an examination (Olatoye \& Afuwape as cited in Olorunfemi-Olabisi, 2014). According to Farooqi, Ghani and Speilberger (as cited in Akinsola \& Nwajei, 2012), test anxiety is a psychological condition in which people experience extreme distress and anxiety in testing situations. While many experience some degree of distress and anxiety before and during test, anxiety can actually impair learning and hurt test performance. Dusek (as cited in Farooqi, Ghani \& Speilberger, 2012) described test anxiety as an unpleasant feeling or emotional state that has both physiological and behavioural components and that is experienced in formal testing or other evaluative situations. According to Ergene (2003), in test anxiety literature, Speilberger's test anxiety definition of 1972 is widely accepted. Speilberger (1972) defined test anxiety as an unpleasant state characterized by feelings of tension and apprehension, worrisome thoughts and the activation of the autonomic nervous system when an individual faces evaluative achievementdemanding situations.

Ziedner (as cited in Akinsola \& Nwajei, 2013) identified and described three components of test anxiety, namely, cognitive, affective and behavioural. The cognitive component involves worry or negative thoughts, depreciating self-statements that occur during assessments and performance inhibiting difficulties that 
Efficacy of Combined Therapy of Cognitive Restructuring and Study Skills Counselling on Test Anxiety among Senior High School Students in Ghana

may arise from anxiety (e.g. problem in recalling facts, difficulty in reading and understanding questions). The affective component includes the person's appraisal of his or her physiological state such as tension, tight muscles and trembling. The behavioural component, on the other hand, includes poor study skills, avoidance and procrastination of work.

Matto and Nabi (as cited in Parvez \& Shakir, 2014) described the influence of test anxiety on motivation and academic performance. According to them, without any anxiety, most of us would lack the motivation to do anything in life. Therefore, moderate level of test anxiety is essential to motivate students to study and may incline them for better achievement. A high level of anxiety, on the other hand, interferes with concentration and affects our memory. In this way, high test anxiety may be one of the obstacles to academic achievement. If not tackled properly on time, it can have far reaching negative consequences. Similarly, Sarason (as cited in Farooqi, Ghani \& Speilberger, 2012) argued that test anxiety is a major devastating factor for all academic performance from the elementary level to the university level.

Empirical evidence relating to the effects of test anxiety on academic performance has been thoroughly investigated. Several researchers have reported statistically significant inverse relationship (negative correlation) between test anxiety and students' academic achievement (e.g. Cassady \& Johnson 2002; Chapell et al., 2005; Oludipe, 2009; Khalid \& Hasan, 2009; Udeani, 2012; Ali, Awan, Batool \& Muhammad, 2013; Ali \& Moshin, 2013). In other words, students with high test anxiety have low academic performance whereas those with low test anxiety have high academic performance. In Ghana, Ntim (2016) concluded from his study that test anxiety exists among students and discovered that it leads to impaired academic performance. In an earlier study, Bruce (2015) found that test anxiety exists among students and leads to poor academic performance. Test anxiety, therefore, has negative effect on students' academic performance.

The negative effects of test anxiety on academic performance can be explained by two models: the interference 
model and the learning deficit model (Wine as cited in Ossai, 2012). According to the interference model, test anxious students are distracted due to negative thoughts. The learning deficit model, on the other hand, proposes that it is students' ineffective study skills during preparation for a test that causes them to be anxious and which affects performance on the test (Neveh-Benjamin as cited in Ossai, 2012). Therefore, to improve academic performance, counsellors often focus on the underlying causes of test anxiety by utilizing cognitive therapies to modify negative thought patterns and improving study skills (Topman \& Jansen as cited in Ossai, 2012).

However, a meta-analysis conducted by Ergene (2003) on test anxiety reduction interventions has revealed results that are contrary to the learning deficit model. The synthesis of the results showed that study skills training alone had a small effect size $\left(\mathrm{E}_{+}=\right.$ 0.28). This shows that test anxiety cannot be explained by a learning deficit model which indicates the lack of effective study skills is the cause of test anxiety. The results further indicated that among cognitive therapies, cognitive restructuring produced the largest effect size $\left(E_{+}=1.11\right)$. However, the effectiveness of cognitive or behavioural interventions is increased when they are combined with skilled-focused techniques such as study skills training.

Cognitive restructuring therapy involves modifying the negative thought patterns and inappropriate beliefs of a client. The basic assumption of cognitive restructuring therapy is that cognitive, emotional, physiological and behavioural responses are not the mere effect of events, but it is simply due to the interpretation of the events. In this therapy, the counsellor assists the client to identify the maladaptive thoughts and beliefs that are causing the anxiety. Clients are also taught to make adaptive responses or reactions to test situations in order to reduce test anxiety (Meichenbaum \& Butler as cited in Ghamari, Rafeie \& Kiani, 2015). Introducing test anxious students to effective study skills complements cognitive restructuring therapy. In study skills counselling, students are exposed to effective ways of studying and taking tests and examinations. 
Efficacy of Combined Therapy of Cognitive Restructuring and Study Skills Counselling on Test Anxiety among Senior High School Students in Ghana

Although cognitive and skilled-focused techniques are very effective in managing test anxiety, it appears that their effectiveness have not been investigated in Ghana. There is, therefore, the need for an empirical study to be conducted using cognitive and skilled-focused interventions on test anxiety so as to bridge the gap in the literature. The few studies conducted in the country on test anxiety are descriptive in nature (e.g. Atindanbila, Abasimi, Nyarko, \& Adika, 2014; Bruce, 2015; Ntim, 2016). It is against this background that the researchers decided to examine the combined effects of cognitive restructuring therapy and study skills counselling on test anxiety among senior high school students in the Komenda Edina Eguafo Abrem Municipality in Ghana.

The study sought to find out the difference in the test anxiety mean scores of participants exposed to cognitive restructuring therapy and study skills counselling and the control group and also determine the influence of gender on test anxiety among participants in the experimental group.

\section{Research Hypotheses}

The following hypotheses guided the study:

1. $\mathrm{H}_{0}$ : There is no significant difference in the test anxiety mean scores of participants exposed to cognitive restructuring therapy and study skills counselling and the control group.

$\mathrm{H}_{1}$ : There is significant difference in the test anxiety mean scores of participants exposed to cognitive restructuring therapy and study skills counselling and the control group.

2. $\mathrm{H}_{0}$ : There is no significant difference in the test anxiety mean scores of male and female participants exposed to cognitive restructuring therapy and study skills counselling. $\mathrm{H}_{1}$ : There is significant difference in the test anxiety mean scores of male and female participants exposed to cognitive restructuring therapy and study skills counselling. 


\section{Methodology \\ Research Design}

The quasi-experimental, pre-test, post-test control group design was used by the researchers for the study. The design was made up of two groups, namely, experimental group and control group. The experimental group received cognitive restructuring therapy and study skills counselling while the control group did not benefit from the treatment. The quasi-experimental pre-test, posttest control group design can be represented as:

$\begin{array}{llll}\text { Experimental group } & \mathrm{O} 1 & \mathrm{X} & \mathrm{O} 2 \\ \text { Control group } & \mathrm{O} 3 & & \mathrm{O} 4\end{array}$

Figure 1: Design of the study

$\mathrm{O} 1$ and $\mathrm{O} 3$ represent pre-test and $\mathrm{O} 2$ and $\mathrm{O} 4$ refer to post-test. $\mathrm{X}$ presents the treatment.

\section{Population}

The population for this study was all second year senior high School students in the Komenda Edina Eguafo Abrem Municipality of Ghana in the 2017/2018 academic year.

\section{Sample and sampling procedure}

Simple random sampling technique was used to select two schools out of the three senior high schools in the Komenda Edina Eguafo Abrem Municipality. The sample size for the study was 40. This number was divided into two groups of 20 participants each (10 males and 10 females). Simple random sampling was also used to select the 40 respondents to participate in the study. Ethical issues were considered and they included confidentiality and voluntary participation.

\section{Research instrument}

The West Side Test Anxiety Scale was adapted for the study. The scale was developed by Driscoll (2007). It comprises 10 items and measures anxiety impairments, with most items asking directly about performance impairment or about worrying, which interferes with concentration. The response options are 5= 
Efficacy of Combined Therapy of Cognitive Restructuring and Study Skills Counselling on Test Anxiety among Senior High School Students in Ghana

Extremely True; 4= Highly True; 3=Moderately True; 2= Slightly

True; $1=$ Never True. Scores are obtained by summing up the 10 questions. After that, divide the sum by 10 to obtain the test anxiety score. The interpretation of the scores are 1.0$1.9=$ Comfortably low test anxiety; $2.0-2.5=$ Normal or average test anxiety; 2.6-2.9=High normal test anxiety; 3.03.4=Moderately high; 3.5-3.9=High test anxiety; 4.05.0=Extremely high anxiety. Higher scores indicate higher test anxiety. Students whose test anxiety scores fell within 3.0-5.0 were considered eligible for the study and were divided into the two groups; experimental and the control groups.

The instrument was given to experts in guidance and counselling at the University of Cape Coast to ascertain its content validity. A pre-test of the instrument was conducted among students in a senior high school that did not form part of the population of this study. The Cronbach's coefficient alpha yielded an index of 0.76 .

\section{Treatment procedure}

The treatment procedure consisted of three distinct phases as shown below:

\section{Pre-counselling phase}

The researchers administered the adapted version of Westside Test Anxiety Scale to the participants in order to collect the baseline data. After that, the participants were grouped into the experimental and control groups.

\section{Counselling phase}

The counselling session was held one hour twice in a week for six consecutive weeks. The details are as follows:

\section{Session 1: Establishment of relationship}

This session dealt with self-introduction, counsellors' and participants' responsibilities during counselling, goals of counselling and ground rules to guide group interaction. 


\section{Session 2: Concept of test anxiety}

This session covered the explanation of test anxiety, its causes, symptoms and effects on academic performance.

\section{Session 3: Concept of cognitive restructuring}

In this section, cognitive restructuring was explained. The theoretical basis of cognitive restructuring was discussed with a focus on rational emotive behaviour therapy. Issues such as the ABC theory of personality, including maladaptive beliefs or interpretations were discussed.

\section{Session 4: Changing negative thoughts and maladaptive beliefs \\ Cognitive restructuring was used to modify negative perceptions and maladaptive beliefs about test situations. Participants were encouraged to replace their faulty thoughts and unhealthy beliefs with adaptive thought patterns and beliefs.}

\section{Sessions 5-8: Concept of study skills}

This section covered the meaning and importance of study skills. The components of study skills such as memory enhancing strategies, reading skills, note taking skills, consultation, time management and test-taking strategies were discussed as suggested by Awabil (2016). The relationship between test anxiety and poor study skills was also discussed. Clients were encouraged to put into practice all strategies that have been discussed.

\section{Session 9: Review of sessions}

This session covered the review and evaluation of the preceding sessions. After that the counselling intervention was terminated.

\section{Post counselling phase}

Two weeks after the termination of the counselling, the clients were given the adapted version of Westside Test Anxiety Scale to fill in order to ascertain the effects of the intervention on their test anxiety levels. 
Efficacy of Combined Therapy of Cognitive Restructuring and Study Skills Counselling on Test Anxiety among Senior High School Students in Ghana

\section{Data analysis}

The data were analysed using independent samples t-test. The hypotheses were tested at 0.05 level of significance.

\section{Results}

\section{Research hypothesis One}

$\mathrm{H}_{0}$ : There is no significant difference in the test anxiety mean scores of participants exposed to cognitive restructuring and study skills counselling and the control group.

$\mathrm{H}_{1}$ : There is significant difference in the test anxiety mean scores of participants exposed to cognitive restructuring and study skills counselling and the control group.

To find out the statistical difference between the post-test mean scores of participants in the experimental and control groups on test anxiety, the independent samples t-test was conducted. The results are presented in Table 1.

Table 1-Result of independent samples t-test analysis comparing the post-test scores of participants in the experimental and control groups on test anxiety $(n=40)$

\begin{tabular}{lccccc}
\hline Group & Mean & SD & t-value & df & $\begin{array}{l}\text { Sig- } \\
\text { value }\end{array}$ \\
\hline Control & 3.89 & .28 & & & \\
& & & $9.742^{*}$ & 38 & .000 \\
Experimental & 1.91 & .87 & & & \\
& & & & & \\
\hline
\end{tabular}

*Significant, $\mathrm{p}<0.05$

Table 1 presents the result of independent samples t-test analysis comparing the post-test mean scores of participants in the experimental and control groups on test anxiety. The result shows that there was significant difference between experimental group and control group with respect to their test anxiety level $(t=9.742$, $\mathrm{df}=38, \mathrm{p}=.000,2$-tailed) at post-test. Therefore, the null hypothesis is rejected. The result means that there was significant effect of cognitive restructuring and study skills counselling on the test anxiety of participants in the experimental group at post-test. 
In other words, the cognitive restructuring therapy and study skills counselling group showed significantly greater reduction in test anxiety than the control group.

\section{Research hypothesis two}

$\mathrm{H}_{0}$ : There is no significant difference in the test anxiety mean scores of male and female participants exposed to cognitive restructuring and study skills counselling.

$\mathrm{H}_{1}$ : There is significant difference in the test anxiety mean scores of male and female participants exposed to cognitive restructuring and study skills counselling.

One of the objectives of the study was to determine the influence of gender on test anxiety of participants in the experimental group at post-test. To achieve this, the independent samples t-test was deemed appropriate for the analysis. The results are presented in Table 2.

Table 2-Results of independent samples t-test comparing gender on test anxiety of participants in the experimental groups using the post-test scores $(n=20)$

\begin{tabular}{lccccc}
\hline Gender & Mean & SD & t-value & Df & $\begin{array}{l}\text { Sig- } \\
\text { value }\end{array}$ \\
\hline Male & 1.83 & .31 & & & \\
Female & 1.95 & .26 & & & .389 \\
\hline
\end{tabular}

Table 2 presents the influence of gender on test anxiety of participants in the experimental group at post-test. In order to ascertain whether significant difference exits in the post-test mean scores on test anxiety of participants in the experimental group on the basis of gender, the independent samples t-test was computed. The result indicates that there was no significant gender difference in the post-test mean scores on test anxiety $(\mathrm{t}=-.897, \mathrm{df}=18, \mathrm{p}=$ .389, 2-tailed). The null hypothesis is, therefore, retained. The result implies that both genders experienced similar level of test 
Efficacy of Combined Therapy of Cognitive Restructuring and Study Skills Counselling on Test Anxiety among Senior High School Students in Ghana

anxiety in the experimental group at post-test. Therefore, it can be said that the intervention was effective.

\section{Discussion of results}

The result indicated that there was significant effect of cognitive restructuring and study skills counselling on the test anxiety of participants in the experimental group at post-test when compared with the control group. This current discovery is consistent with the findings of Ergene (2003) and Ghamari, Rafeie and Kiani (2015) which stated that participants exposed to both cognitive restructuring and study skills counselling had lower test anxiety as compared with the control. Again, the finding supports previous research findings of Amiri et al. (as cited in Ghamari, Rafeie \& Kiani, 2015) who compared the effectiveness of cognitive-behavioural therapy techniques, learning effective study skills and the mixed method in reducing test anxiety. Their results showed that all the three experimental groups compared with the control group showed a significant decrease in anxiety scores, but the simultaneous application of the cognitive-behavioural therapy and study skills training compared with its separate application caused a significant decrease in the scores of students' test anxiety. In the current study, the significant reduction of the test anxiety of participants in the experimental group as compared to their counterparts in the control group could be attributed to the cognitive restructuring and the study skills counselling intervention. For example, students were taught how to identify and modify negative thoughts and maladaptive beliefs relating to test situations. They were also taught study skills such as how to manage their time effectively and how to memorize and retrieve information.

The results also showed that there was no significant difference in the post-test mean scores on test anxiety of male and female participants in the experimental group. This finding is in line with the finding of Akinsola and Nwajei (2013) which indicated that there was no significant difference in the test anxiety levels of both males and females at post-test. In contrast, the 
current finding does not agree with the results of descriptive studies obtained by Ngwoke, Ossai and Obikwelu (2013), Farooqi, Ghani \& Speilberger (2012), Syokwaa, Aloka and Ndunge (2014) and Malhotra (2015) which revealed significant gender differences in test anxiety.

The current finding suggests that both genders experienced almost similar level of test anxiety in the experimental group after the intervention. This implies that both genders benefited equally from the intervention. The failure to find significant gender differences could be attributed to the fact that both male and female participants were equally motivated to have a reduction in their test anxiety.

\section{Conclusions and Recommendations}

Based on the findings, the following conclusions and recommendations are made.

It can be concluded that the combined therapy of cognitive restructuring and study skills counselling is an effective intervention for managing test anxiety among senior high school students. Gender is not a significant determinant of test anxiety among senior high school students at post-test. It is, therefore, recommended that in the pursuit of helping to reduce or manage test anxiety among senior high school students, counsellors should combine cognitive restructuring therapy with study skills counselling. It is also recommended that school counsellors should organize seminars and workshops to orient and train teachers on how to effectively use the cognitive restructuring technique and study skills counselling in the classroom so as to improve students' academic performance by minimizing test anxiety levels of students. 
Efficacy of Combined Therapy of Cognitive Restructuring and Study Skills Counselling on Test Anxiety among Senior High School Students in Ghana

\section{References}

Ali, M. S., \& Moshin, M. N. (2013). Relationship of test anxiety with students' achievement in science. International Journal of Educational Science and Research, 3(1), 99106.

Ali, M. S., Awan, A. S., Batool, S., \& Muhammad, N. (2013). Secondary school students' test anxiety and achievement in English. International Journal of English and Literature, 3(1), 131-138.

Akinsola, E. F., \& Nwajei, A. D. (2013). Test anxiety, depression and academic performance: Assessment and management using relaxation and cognitive restructuring techniques. Psychology, 4(6), 18-24.

Atindanbila, S., Abasimi, E., Nyarko, K., \& Adika, J. A. (2014). The occurrence of test anxiety in student nurses in selected nursing schools in Ghana. American Journal of Applied Psychology, 3(1), 21-26.

Awabil, G. (2016). Introduction to study skills for students in higher education. Accra: Adwinsa Publications (Gh) Ltd.

Bruce, D. (2015). Mathematics anxiety among Ghanaian students: A study of students in Kinbu Senior High/Technical School, Accra and Herman-Gmeiner SOS Junior High School, Tema. Journal of Education and Practice, 7(15), 75-83.

Cassady, J. C., \& Johnson, R. E. (2002). Cognitive test anxiety and academic performance. Contemporary Educational Psychology, 27(2), 270-295.

Chapell, M. S., Blanding, Z. B., Takahashi, M., Silverstein, M.E., Newman, B., Gubi, A., \& Mccann, N. (2005). Test anxiety and academic performance in undergraduate and graduate students. Journal of Educational Psychology, 97(2), 268274.

Driscoll, R. (2007). Westside test anxiety scale validation.

Retrieved frohttps://files.eric.ed.gov/fulltext/ED495968.pdf 
Ergene, T. (2003). Effective interventions on test anxiety reduction: A meta-analysis. School Psychology International, 24(3), 313-328.

Farooqi, Y. N., Ghani, R., \& Spielberger, C. D. (2012). Gender differences in test anxiety and academic performance of medical students. International Journal of Psychology and Behavioral Sciences, 2(2), 38-43.

Ghamari, K. H., Rafeie, S. H., \& Kiani, A. R. (2015). Effectiveness of cognitive restructuring and proper study skills in the reduction of test Anxiety symptoms among students in Khalkhal, Iran. American Journal of Educational Research, 3(10), 1230-1236.

Khalid, R., \& Hasan, S.S (2009). Test anxiety in high and low achievers. Pakistan Journal of Psychological Research, 24(3-4).

Malhotra, T. (2015). Exam anxiety among secondary school students. Scholarly Research Journal for Interdisciplinary Studies, 3(17), 3089-3098.

Ngwoke, D. U., Ossai, O. V., Obikwelu, C. L. (2013). Influence of study skills on test anxiety of secondary school students in Nsukka Urban, Enugu State, Nigeria. Journal of Education and Practice, 4(17), 162-165.

Ntim, S. (2016). Do restrictions in working memory capacity account for decrement in cognitive performance on highly test-anxious individuals? A study among selected Ghanaian university students. Internal Journal of Applied Psychology, 2(2), 704-710.

Olorunfemi-Olabisi, F. A. (2014). Effects of problem solving technique on test anxiety and academic performance among secondary school students in Ondo State. Journal of Research and Method in Education, 4(4), 20-26.

Oludipe, B. (2009). Influence of test anxiety on performance levels on numerical tasks of secondary school physics students. Academic Leadership Journal, 7(4). 
Efficacy of Combined Therapy of Cognitive Restructuring and Study Skills Counselling on Test Anxiety among Senior High School Students in Ghana

Ossai, O. V. (2012). Influence of study skills on test anxiety levels and achievement of senior secondary school students in English language. Unpublished master's research project, University of Nigeria, Nsukka.

Parvez, M., \& Shakir, M. (20014). Academic achievement of adolescents in relation to academic anxiety, gender and choice of academic stream. Research on Humanities and Social Sciences, 4(12), 107-115.

Spielberger, C. (1972). Anxiety as an emotional state. In C. D. Spielberger(Ed.),Anxiety: Current trends in theory and research ( pp. 23-49). New York, NY: Academic Press.

Syokwaa, K. A., Aloka, P. J., \& Ndunge, S. N. F. (2014). The relationship between anxiety levels and academic achievement among students in selected secondary schools in Lang'ata District, Kenya. Journal of Educational and Social Research, 4(3), 403-415.

Udeani, U. (2012). The relationship between study habits, test anxiety and science achievement. Journal of Education and Practice, 3(8), 151-157. 